DOI 10.14526/2070-4798-2019-14-1-74-80

\title{
Criteria of physical fitness level evaluation at representatives of different shock types of the olympic single combats
}

\author{
Oleg G. Epov ${ }^{1 *}$, Aleksey V. Meshcheryakov² \\ ${ }^{1}$ Russian State University of Physical Culture, Sport, Youth and Tourism (GTSOLIFK) \\ Moscow, Russia \\ ORCID: 0ooo-0o03-3820-0991, neg7564@yandex.ru \\ ${ }^{2}$ Ulyanov State Pedagogical University, Ulyanovsk, Russia \\ ORCID: 000o-0003-4371-8920, aleksei236632@yandex.ru
}

\begin{abstract}
Impact types of Olympic martial arts, despite the differences determined by the rules of the competition, make significant demands along with technical tactics and physical fitness. Assessment of athletes physical fitness level is always a pressing issue at all levels of training. Testing seems to be the most versatile assessment method. Materials. The paper proposes a comparative approach to assessing and improving the training and competitive activities of highly qualified athletes. Indicators are presented that reveal the level of Olympic martial arts percussion types top athletes preparedness, obtained by testing on a bicycle ergometer and treadmill. The study determined energy thresholds and maximum oxygen consumption. Research methods. Generalization of advanced pedagogical experience of coaches in taekwondo and boxing, analysis of scientific and methodological literature, testing, pedagogical experiment, statistical data processing. Results. In the materials of the article physiologo-pedagogical interpretation of information about the physical training of athletes is done. It is identified on the basis of the used methods. The analysis made it possible, when testing on treadmill between athletes of Olympic martial arts (boxing and taekwondo) percussion types, to note significant differences in terms of heart rate and running speed at the level of anaerobic threshold and maximum running speed. Athletes (WTF) showed better results when tested on the "foot" bicycle ergometer, and when tested on the "manual" bicycle ergometer, the performance indicators are higher in athletes boxers. Conclusion. The results of the pedagogical experiment allowed to draw a conclusion about the expediency and effectiveness of the comparative approach use in assessing the level of highly skilled athletes physical fitness. They made it possible to identify both general and particular features of fitness. The results obtained corrected the training plan of the athletes-taekwondo players, which made it possible to significantly improve the performance of competitive activities.
\end{abstract}

Keywords: taekwondo, boxing, Olympic types of single combats, maximum consumption of oxygen, bicycle ergometer.

For citation: Oleg G. Epov*, Aleksey V. Meshcheryakov. Criteria of physical fitness level evaluation at representatives of different shock types of the olympic single combats. The Russian Journal of Physical Education and Sport. 2019; 14(1): 64-69. DOI 10.14526/2070-4798-2019-14-1-74-80

\section{Introduction}

Currently, in the system of sports training, the principle of specialization is one of the fundamental $[2,8,10]$. At the same time, progressive innovations in the training process carried out in other sports, similar in dynamics, biomechanics of movements, intensity of competitive activity, are overlooked by coaches. There is no doubt that the transfer of best practices, creative ideas and pedagogical techniques of athletes. For this purpose, it is possible to conduct research on the level of related sports athletes various qualities development, in particular Olympic martial arts [9,10,11]. Currently, one of the available means of testing in the laboratory is a Bicycle Ergometer and treadmill.

Scientists analyze the sports results of the country and the world strongest athletes. Aerobic and anaerobic thresholds, maximum oxygen consumption, maximum anaerobic power are 
recognized as the main indicators approved for the assessment of athletes' performance [12,13].

Based on the known data of knowledge about the physical fitness of athletes use to control the process of improving sports and technical skills, a working hypothesis was formulated about the possibility of improving the efficiency of sports and technical training of taekwondists. It was process based on the information provided to the coach about the preparedness level in training and competition. This will make it possible to deepen the individualization of training effects. It was assumed that the increase in the effectiveness of sports training will largely be determined by the completeness of assessments and interpretations of the information received by the coach.

To test the hypothesis, a comparative study was undertaken. The following tasks were set in it:

1. To identify the informative value of physiological characteristics for the diagnosis of physical fitness in order to improve the effectiveness of training.

2. To determine the indicators characterizing the preparedness of highly qualified athletes of shock types of Olympic martial arts in the annual cycle of training.

3. To compare performance of Olympic single combats shock types athletes at testing on the Bicycle Ergometer and treadmill.

4. Make a correction to the individual plans of the annual training cycle, taking into account the information obtained in the study.

\section{Materials and methods}

The study involved highly qualified athletes of Taekwondo specialization (WTF) - 26 people aged $23 \pm 4.2$ years, and Boxing specialization 24 people aged $22 \pm 2.9$ years (masters of sports, masters of sports of international class).

All athletes were tested for 4 days in the form of a step-increasing load on the treadmill "h / pCosmos". Test Protocol: initial speed of $5 \mathrm{~km} / \mathrm{h}$, increasing every 2 minutes by $2 \mathrm{~km} / \mathrm{h}$.the Test was performed to failure. During the test, the parameters of external respiration were measured using a gas analyzer "Cortex", "Metalyzer 3B-R2", fixed heart rate. Used veloergometr "Monark 891E"("foot").

\section{Results and discussion}

As a result of scientific and methodical literature studying, interviews with leading coaches and experts of the sports and sports medicineresearch Institute Rgufksmit were identified informative physiological characteristics for the diagnostics of single combats shock types athletes physical fitness. They had aim of improving the effectiveness of training. Aerobic threshold characterizes the power of the tested muscle groups' oxidative muscle fibers [7]. The aerobic threshold defines the level of general endurance. As a rule, aerobic threshold is fixed at the concentration of lactic acid $2 \mathrm{mmol} /$ 1. [2]. The higher the level of anaerobic threshold, the greater the load the body can perform for a considerable time without reducing work power [3]. The value of the anaerobic threshold indicates the level of muscles speed-strength endurance. Energy thresholds were determined by the method of V.N. Seluyanov, E. M. Kalinin, G. D. Pak [6].

The maximum oxygen consumption (MOC) determined in the study when performing the proposed load made it possible to determine the overall aerobic performance $[4,5,8]$. MOC was recorded at the time of load failure [11].

As a result of athletes specializing in Taekwondo (WTF) physical performance study when comparing testing facilities (veloergometer and treadmill) indicators characterizing their preparedness were identified. The data are presented in table 1.

The study revealed significant differences in the same group of athletes. They performed testing on a Bicycle Ergometer and treadmill. On the treadmill all fixed values were much higher than on the Bicycle Ergometer. Such values when running on the treadmill can be explained by the fact that the running involved a greater number of muscles compared to those tested on the Bicycle Ergometer, namely: the muscles of the ankle flexors, the back of the thigh, respiratory muscles, and also produced active mach hands. The results of the study are presented in table 2. 
Table 1-Comparative analysis of methods for determining the anaerobic threshold in athletes on a Bicycle Ergometer and treadmill

\begin{tabular}{|c|c|c|c|c|c|}
\hline \multirow{2}{*}{$\begin{array}{l}\text { Name of } \\
\text { indicators }\end{array}$} & \multicolumn{2}{|c|}{ Ergometer } & \multicolumn{2}{|c|}{ Trebon } & \multirow{2}{*}{$\mathrm{p}$} \\
\hline & $\mathrm{X}$ & $\sigma$ & $\mathrm{X}$ & $\sigma$ & \\
\hline Weight, kg & 75,5 & 11,5 & 76,7 & 11,3 & 0,1 \\
\hline AnT, W & 212 & 35,5 & - & - & 0,001 \\
\hline AnT, km/h & - & - & 12,2 & 0,8 & - \\
\hline AnT, $1 / \min$ & 2,9 & 0,4 & 3,7 & 0,6 & 0,001 \\
\hline AnT, $\mathrm{ml} / \mathrm{kg}$ & 38 & 2,2 & 49,0 & 4,1 & 0,001 \\
\hline AnT, VE, l/min & 76 & 10,8 & 104,0 & 17,0 & 0,01 \\
\hline $\begin{array}{c}\text { HR AnT, } \\
\text { beat } / \mathrm{m}\end{array}$ & 160 & 9,3 & 178,0 & 6,8 & 0,001 \\
\hline $\begin{array}{c}\mathrm{VO} 2 \max , \mathrm{l} / \\
\min \end{array}$ & 3,9 & 0,4 & 4,2 & 0,6 & 0,05 \\
\hline $\begin{array}{c}\mathrm{VO} 2 \max , \mathrm{ml} / \\
\mathrm{kg}\end{array}$ & 51,8 & 2,5 & 55,4 & 4,3 & 0,005 \\
\hline
\end{tabular}

Table 2-Comparative analysis of athletes physical performance on the treadmill

\begin{tabular}{|c|c|c|c|c|c|}
\hline \multirow{2}{*}{ The performance of criteria } & \multicolumn{2}{|c|}{ Boxing $\mathrm{n}=24$} & $\mathrm{t}$ & \multicolumn{2}{c|}{$\begin{array}{c}\text { Taekwondo } \\
\text { (WTF) } \mathrm{n}=26\end{array}$} \\
\cline { 2 - 6 } & $\mathrm{x}$ & $\sigma$ & & $\mathrm{x}$ & $\sigma$ \\
\hline $\begin{array}{c}\text { Heart rare at AND, beats/ } \\
\text { min }\end{array}$ & 176 & 2,4 & $6,8^{*}$ & 166 & 3,4 \\
\hline Speed at ANP, m/sec & 3,8 & 0,18 & $10,2^{*}$ & 3,0 & 0,35 \\
\hline ANP, ml/min/kg & 44,8 & 5,0 & 0,8 & 43,7 & 3,7 \\
\hline IPC, ml/min/kg & 56,0 & 5,42 & 1,06 & 57,3 & 2,6 \\
\hline $\begin{array}{c}\text { Maximum speed in the test, } \\
\text { m/sec }\end{array}$ & 4,7 & 0,33 & $3,4^{*}$ & 4,4 & 0,28 \\
\hline Heart rate max, beats/min & 195 & 9,17 & 0,8 & 193 & 8,46 \\
\hline Lamax, mm/l & 9,7 & 1,5 & 1,7 & 10,4 & 1,43 \\
\hline \%ANP/IPC & 80 & 5 & 2,8 & 76 & 5 \\
\hline Note - * at $\mathrm{t} \geq 2,02, \mathrm{p}<0,05$. & \multicolumn{5}{l}{} \\
\hline
\end{tabular}

As a result of shock types of the Olympic single combats between athletes comparative research reliable differences in indicators of run speed and heart rate at the level of the anaerobic threshold and the maximum speed of run reached in the test were received; differences are reliable $(\mathrm{p}<$ 0.05).

However, in terms of oxygen consumption at the level of ANP and MOC, the maximum lactate concentration, the maximum heart rate at the end of the test, no significant differences were found ( $p>$ 0.05).

Consequently, significant differences in the performance of athletes is not observed except
Boxing compared to those of Taekwondo. There was a significant difference in the speed of running at the level of ANP between athletes-boxers and taekwondists, while the oxygen consumption differences were not revealed. It is noted that the maximum concentration of lactate at the end of the test in athletes does not differ as much as the IPC and heart rate, while there are differences in the achieved maximum speed of running.

Further, a comparative analysis of shock martial arts highly qualified athletes test results on the foot Bicycle Ergometer was carried out.

All athletes without warm-up performed pedal rotation at a constant speed of $75 \mathrm{rpm}$, despite the increase in load power. The initial load power is 
$38 \mathrm{~W}$ for $2 \mathrm{~min}$. It is automatically increased by $38 \mathrm{~W}$. At the same time we spent fixing HR and measured the $\mathrm{O} 2$ consumption and the allocation of $\mathrm{VCO} 2$. The test is performed to failure or inability of the athlete to maintain a given speed. Determination of

Table 3-Comparative analysis of athletes physical performance when tested on a foot Bicycle Ergometer

\begin{tabular}{|c|c|c|c|c|c|}
\hline \multirow{2}{*}{ Indicators } & \multicolumn{2}{|c|}{ Boxing $\mathrm{n}=27$} & \multirow{2}{*}{$\mathrm{t}$} & \multicolumn{2}{|c|}{ Taekwondo (WTF) $n=21$} \\
\hline & $\mathrm{X}$ & $\sigma$ & & $\mathrm{X}$ & $\sigma$ \\
\hline Weight, kg & 76,4 & 10,95 & 0,3 & 77,6 & 11,0 \\
\hline AEP Heart rate, beats/min & 126,4 & 2,51 & 0,8 & 128,5 & 12,5 \\
\hline $\mathrm{AEP}, \mathrm{ml} / \mathrm{min} / \mathrm{kg}$ & 21,2 & 3,48 & 3,2 & 24,6 & 4,0 \\
\hline ANP Heart rate, beats/min & 154 & 7,9 & 2,0 & 158,8 & 9,2 \\
\hline $\mathrm{ANP}, \mathrm{ml} / \mathrm{min} / \mathrm{kg}$ & 34,4 & 7,42 & 5,2 & 43,1 & 3,6 \\
\hline $\mathrm{IPC} \mathrm{ml} / \mathrm{min} / \mathrm{kg}$ & 57,3 & 5,83 & 1,2 & 59,6 & 8,0 \\
\hline MA W/kg & 11,9 & 0,83 & 5,5 & 13,1 & 0,7 \\
\hline Lamax, $\mathrm{mm} / \mathrm{l}$ & 11,5 & 1,3 & 5,9 & 9,4 & 1,2 \\
\hline
\end{tabular}

In accordance with table 3 , there are significant differences between athletes $(\mathrm{p}<0.05)$ in terms of $\mathrm{O} 2$ consumption at the level of aerobic and anaerobic thresholds, maximum alactate power, maximum lactate concentration at the end of the test. Values are higher in Taekwondo (WTF) athletes.

There is no doubt that the specificity of the sport has an impact on the preparedness assessed in the study when pedaling on a Bicycle Ergometer. Obviously, this is due to the fact that for athletes specializing in Taekwondo, the main shock link and active muscles are the leg muscles. While for athletes specializing in the box muscles of the shoulder girdle. Leg muscles are only stabilizers at the beginning of attacking actions and contribute to the movement of athletes in the ring area [10,14]. Leg muscles do not participate in the main motor actions. Therefore do not perform the main overcoming and conceding work. It can not be said about those in Taekwondo athletes (WTF). In addition to shock actions with their feet, it is necessary to perform movements on the carpet area during the transition to defensive and attacking actions $[4,15,16]$.

It was suggested that since the work of the shoulder girdle muscles is more typical for athletesboxers, the performance of the shoulder girdle muscles will vary significantly compared to those of the maximum anaerobic power (MAP) was carried out in the form of the maximum acceleration on the monark 839e Bicycle Ergometer. The results of the study are presented in table 3 .

Taekwondo (WTF) specialization representatives. The study involved the same group of highly qualified athletes. It becomes relevant to conduct a comparative analysis of the athletes performance when tested on a hand Bicycle Ergometer. Athletes performed the test on a manual Bicycle Ergometer: rotation of pedals by hands at a constant speed of 75 revolutions per minute at increase in power of loading. The initial load power is 19 watts lasting for 2 minutes; the capacity is automatically increased by 19 watts. There was also fixation of heart rate, measurement of $\mathrm{O} 2$ consumption and allocation of VCO2. The results of the studies are presented in table 4 .

When working with hands, highly qualified athletes-boxers are superior in most performance indicators of the Taekwondo specialization (WTF) representatives, determined by a manual Bicycle Ergometer, but the differences are unreliable $(p>0.01)$.

\section{Conclusion}

In the current study when testing on a treadmill between athletes impact Olympic martial arts (Boxing and Taekwondo) were obtained significant differences for the heart rate and running speed at the level of anaerobic threshold and maximum running speed. Taekwondo athletes 
showed better results. When testing for the leg Ergometer also higher performance observed in athletes specialization Taekwondo (WTF). When you test on hand cycle Ergometer health indicators are higher in athletes-boxers. Similar results were

Table 4-Comparative analysis of athletes physical performance when tested on a hand Bicycle Ergometer

\begin{tabular}{|c|c|c|c|c|c|}
\hline \multirow{2}{*}{ Data } & \multicolumn{2}{|c|}{ Boxing $\mathrm{n}=\mathbf{2 7}$} & \multirow{2}{*}{$\mathrm{t}$} & \multicolumn{2}{|c|}{ Taekwondo (WTF) $\mathrm{n}=\mathbf{2 1}$} \\
\cline { 6 - 6 } \cline { 5 - 6 } & $\mathrm{x}$ & $\sigma$ & & $\mathrm{x}$ & $\sigma$ \\
\hline Weight, kg & 76,4 & 10,95 & 0,3 & 77,6 & 11,0 \\
\hline AEP Heart rate, beats/min & 133,0 & 9,0 & 3,8 & 121 & 12,9 \\
\hline AEP ml/min/kg & 14,7 & 2,7 & 4,2 & 19,1 & 4,5 \\
\hline ANP Heart rate, beats/min & 153,0 & 7,6 & 5,4 & 139 & 10,6 \\
\hline ANP ml/min/kg & 24,7 & 2,6 & 8,0 & 30,6 & 2,6 \\
\hline MA W/kg & 10,0 & 1,3 & 4,5 & 12,0 & 1,8 \\
\hline Lamax, mm/l & 8,3 & 1,1 & 3,4 & 7,2 & 1,2 \\
\hline
\end{tabular}

Based on the results, made and presented recommendations for coaches of tested athletes. It should be noted that athletes of Taekwondo specialization (WTF) are tested during complex examinations most often using treadmill to obtain data on aerobic performance of the body.

Thus, informative indicators of testing provide objective information and allow to adjust the training load, to develop practical recommendations. They take into account the individual characteristics of the athlete and specifics of the sport.

\section{References}

1. Makinchenko E.B., Turaev V.T. Biological patterns in planning of physical preparation of sportsmen. Teoriya I praktika fizicheskoj kul'tury = Theory and practice of physical culture. 1993; 7: 29-33 (In Russ., In Engl.).

2. Abalyan A.G. Features of the organization of scientific and methodological support for the preparation of sports teams of the Russian Federation. Teoriya I praktika fizicheskoj kul'tury: trener. 2011; 11: 66-70 (In Russ.).

3. Pavlova V.I., Terzi M.S., Sigal M.S. The ratio of the volume of aerobic and anaerobic training load in accordance with the specifics of the energy aspects of performance in acyclic sports: on the example of Taekwondo. Teoriya I praktika fizicheskoj kul'tury $=$ Theory and practice of physical culture. 2002; 10: 53-54 (In Russ., In Engl.). obtained by researchers when comparing the physical performance of martial artists (Sambo and judo) [1].

\section{4 .}

Seluyanov

V.N. Mathematical modeling of metabolic processes in muscle fibers. Sbornik trudov uchenyh RGUFKSiT: materialy nauchnoj konferencii professorskoprepodavatel'skogo sostava RGUFKCiT [Collection of scientific notes of scientists of RGUFKSIT: materials scientific conference of RGUFKSIT's professors and lecturers. M. 2009: 81-84 (In Russ.).

5. Seluyanov V.N., Kalinin E.M., Pak G.D. Determination of anaerobic threshold according to pulmonary ventilation and variability of cardiointervals. Fiziologiya cheloveka. 2011; 37(6): 1-5 (In Russ.).

6. Shulika Yu.A. Long-term technical and tactical training of wrestlers. Doctor's thesis. : M. 1990: 37.

7. Shin A.P.G., Epov O.G. Evaluation Criteria of physical preparedness of athletes of high qualification athletes of different weight categories. Uchenye zapiski universiteta imeni P.F. Lesgafta. 2015; 9: 207-210 (In Russ.).

8. Epov O.G., Meshcheryakov A.V. A New way of implementation of shock equipment in Taekwondo. Uchenye zapiski universiteta imeni P.F. Lesgafta. 2015; 9(127): 215-218 (In Russ.).

9. Epov O.G. Conjugate training for legs muscles in micro cycle of training for competitions among athletes of high qualification in taekwondo WTF. Pedagogiko-psikhologicheskie i medico-biologicheskie problem fizicheskoy 
kultury i sporta $=$ The Russian Journal of Physical Education and Sport. 2018; 13(2): 62-67. DOI: 10.14526/02_2018_311 (In Russ., In Engl.).

10. El-Ashker S. Effects of developing complex motor skills on technical performance effectiveness of junior boxers. Mansoura University, Egypt. 2010.

11. Fairbrother J.T. Fundamentals of Motor Behavior. (Champaign, USA: Human Kinetics). 2010.

12. Hlustik P., Solodkin A., Noll D.C., Small S.L. Cortical plasticity during threeweek motor skill learning. Journal of Clinical Neurophysiology. 2004; 21(3): 180-191.

13. Raab M. Decision making in sports: Influence of complexity of implicit and

Submitted: 15.02.2019

\section{Author's information:}

Oleg G. Epov * - Candidate of Pedagogics, Professor, Russian State University of Physical Culture, Sport, Youth and Tourism (GTSOLIFK), 105122, Russia, Moscow, Sirenevy Boulevard, House 4, e-mail: neg7564@yandex.ru

Aleksey V. Meshcheryakov - candidate of Biological Sciences, Associate Professor, Ulyanov State Pedagogical University, Ulyanovsk, Russia, 43270o, Square 10o-anniversary of Birthday of V. I. Lenin, House 4, e-mail: aleksei236632@yandex.ru explicit learning. International Journal of Sport and Exercise Psychology. 2003; 1: 310-337.

14. Shima K., Tanji J. Neuronal activity in the supplementary and presupplementary motor arears for temporal organization of multiple movements. Journal of Neurophysiology. 2000; 84: 2148-2160.

15. Voelcker C., Wiertz O., Willimczik K. Lifespan motor development - a re-interpretation of investigations on motor learning. Psychologie and Sport. 1999; 6: 90-101.

16. Williams A.M., Ward P. Developing perceptual expertise in sport. In J.L. Starkes, K.A. Ericsson (Eds.), Expert Performance in Sports: Advances in Research on sport Expertise. Champaign, USA: Human Kinetics. 2003: 219-250. 